\title{
Avaliação ovariana em vacas com endometrite utilizando a ultrassonografia Doppler
}

Bruno Leonardo Mendonça Ribeiro, Enoch Brandão de Souza Meira Júnior, Mario Augusto Aleman Reyes, Eduardo Carvalho Marques, Natália Carrillo Gaeta, Lilian Gregory

Faculdade de Medicina Veterinária e Zootecnia, Universidade de São Paulo (USP), São Paulo, SP, Brasil

*Autor correspondente

e-mail: brunolmribeiro@gmail.com

\section{Resumo}

A bovinocultura leiteira é uma importante atividade econômica no Brasil. Em consequência disso, os animais são exigidos quanto a sua produtividade (reprodução e produção leiteira). Essa exigência relacionase a diferentes fatores como: alterações nos níveis hormonais, perdas embrionárias, aumento de dias abertos e maior incidência de problemas reprodutivos. As doenças uterinas no pós-parto, como a metrite e endometrite, são prevalentes em vacas principalmente com aptidão leiteira. Uma patologia muito comum nesse período é a endometrite (processo inflamatório superficial do endométrio), que promove, entre outros sinais clínicos, o retorno irregular ao cio, reduzindo o índice reprodutivo dos animais. Com o intuito de se obter novas ferramentas diagnósticas que proporcionem resultados rápidos de patologias reprodutivas, fazse uso da ultrassonografia Doppler, que fornece informações em tempo real sobre os aspectos vasculares e hemodinâmicos de tecidos. A vascularização ovariana é bem utilizada na área de reprodução animal, já que auxilia na determinação do melhor momento para realizar a inseminação artificial, além de identificar animais prenhes precocemente. 0 objetivo desse estudo foi descrever as alterações hemodinâmicas nos ovários de fêmeas bovinas, causadas pela endometrite, por meio da ultrassonografia Doppler. Realizou-se o exame ginecológico e obstétrico em 89 vacas Holandesas, entre 25 a 35 dias pós-parto, utilizando a vaginoscopia, ultrassonografia convencional e Doppler, além de citologia. Dessas vacas, 33 eram sadias (controle) e 56 diagnosticadas com endometrite por meio de citologia ( $>10 \%$ de polimorfonucleares). Após a avaliação ovariana, observou-se a predominância de animais com endometrite que não apresentavam corpo lúteo (CL) tanto no ovário direito $(64,00 \% ; P=0,047)$ como no esquerdo $(69,09 \% ; P=0,004)$. Além disso, a ausência de vascularização no CL direito e esquerdo de animais com endometrite foi de 61,54 \% e 52,94\%, respectivamente. A fim de verificar a influência dos ovários e a sua vascularização frente à presença de corpo lúteo em animais com endometrite, realizou-se por intermédio da técnica Doppler cores a análise colorimétrica do corpo lúteo. Observou-se 
que animais com ausência de vascularização em corpo lúteo (CLv) direito (63,79 \%) e esquerdo (70,49 \%) apresentavam endometrite. Verificou-se que, mesmo os animais apresentando ciclo estral regular diante da endometrite, houve interferência na reprodução. A utilização de novas técnicas, menos invasivas e de rápido resultado como a ultrassonografia Doppler, podem fornecer respostas importantes quanto à evolução de alterações ovarianas e, com isso, associar os resultados à precocidade reprodutiva. 